\title{
Effect of inoculation of Carnobacterium divergens V41, a biopreservative strain against Listeria monocytogenes risk, on the microbiological, chemical and sensory quality of cold-smoked salmon
}

\author{
Anne Brillet ${ }^{a}$, Marie-France Pilet ${ }^{a}$, Hervé Prevost ${ }^{a}$, Mireille Cardinal ${ }^{b}$ and Françoise Leroi $^{b^{*}}$ \\ aLaboratoire de Microbiologie Alimentaire et Industrielle, ENITIAA, BP 82225, 44322 Nantes Cedex 3, France \\ bLaboratoire de Génie Alimentaire, IFREMER, Rue de l'Ile d'Yeu, BP 21 105, 44311 Nantes Cedex 3, France \\ *: Corresponding author : Tel.: +33 2403741 72. fleroi@ifremer.fr
}

\begin{abstract}
The aim of this study was to develop a biopreservation strategy for cold-smoked salmon (CSS) by the use of lactic acid bacteria previously selected for their capability to inhibit the growth of Listeria monocytogenes in the product. The spoiling potential of three Carnobacterium strains (Carnobacterium divergens V41, Carnobacterium piscicola V1 and SF668) was tested in sterile CSS blocks inoculated by 104-5 CFU g- 1 and stored under vacuum for 9 days at $4{ }^{\circ} \mathrm{C}$ followed by 19 days at $8{ }^{\circ} \mathrm{C}$. C. divergens $\mathrm{V} 41$ grew a little faster than the other strains and none of the three carnobacteria showed any adverse effect on quality of the product, i.e. no off-odour detected by a trained panel, no total volatile basic nitrogen (TVBN) production, no acidification and no biogenic amine except a slight production of tyramine. An application on commercial CSS was tested by spraying C. divergens V41 (104-5 CFU g- 1) on slices of four batches freshly processed in different smokehouses. Microbial, chemical and sensory characteristics were weekly compared to a control during 4 weeks of vacuum storage. When the natural microflora was initially weak (two batches $<20$ CFU $g-1$ ), C. divergens V41 quickly reached 107-8 CFU g- 1 and a slight inhibition of endogenous Enterobacteriaceae, lactobacilli and yeasts was observed. The presence of C. divergens V41 was slightly detected (odour and flavour) but none of the sample was considered as spoiled by the sensory panel. When the natural microflora was initially high ( 2 batches $>104-5$ CFU g- 1), no effect on the microflora, TVBN and biogenic amine production, nor on the sensory characteristics was observed in presence of $C$. divergens V41. In conclusion, biopreservation of CSS using lactic acid bacteria such as C. divergens V41 is a promising way to inhibit the growth of pathogenic bacteria such as L. monocytogenes with low effect on the quality of the product.
\end{abstract}

Keywords: Cold-smoked salmon; Biopreservation; Carnobacterium; Spoilage microflora; Biogenic amine; Sensory analysis 


\section{Introduction}

The production of CSS within the European community supplies nearly $80 \%$ of the world market with an annual production rising 70000 tonnes (FAO, 2003). France is the first worldwide producer with approx. 19000 tones/year but other countries such as Denmark, Germany and United Kingdom have recently increased there production. Salting and smoking treatments which were traditionally used as preservation technology are nowadays lighter leading to highly perishable product, with an average salt content of around $5 \%$ (water phase) in Europe and phenol content less than $1 \mathrm{mg} 100 \mathrm{~g}^{-1}$ (Cardinal et al., 2004). The major risk associated with this product is Listeria monocytogenes (Bledsoe et al., 2001). L. monocytogenes is of special concern to the CSS industry because it is able to grow at low temperature and in presence of high $\mathrm{NaCl}$ concentration. Indeed, a high prevalence of $L$. monocytogenes in CSS has been reported (Ben Embarek, 1994; Rorvik et al., 1995; Heinitz and Johnson, 1998; Jorgensen and Huss, 1998) and the processing steps (i.e. salting and smoking) are insufficient to inactivate this pathogenic bacterium (Guyer and Jemmi, 1991; Ribeiro Neunlist, in press). Moreover growth in the final product stored at chilled temperature is possible (Jorgensen and Huss, 1998; Duffes et al., 1999a; Nykanen et al., 2000) and L. monocytogenes can reach $100 \mathrm{CFU} \mathrm{g}^{-1}$ which is the maximum tolerable limit till the sell-by date in many European countries. Recently, a biopreservation strategy for this product has been developed. Biopreservation consists in inoculating food product by selected bacteria to inhibit the growth of undesired micro-organisms, without changing quality of the product. The inhibition capacity of three bacteriocin-producing strains isolated from seafood, Carnobacterium divergens V41, C. piscicola V1 and C. piscicola SF668, has been demonstrated against a wide collection of $L$. monocytogenes both in agar plate and in sterile CSS blocks artificially contaminated (Brillet et al., 2004). The three carnobacteria strains gave promising results, $C$. divergens V41 being the most efficient strain, maintaining the level of $L$. monocytogenes lower than $50 \mathrm{CFU} \mathrm{g}^{-1}$ (initial contamination : $20 \mathrm{CFU} \mathrm{g}^{-1}$ ) during the four weeks of vacuum storage at $4^{\circ}$ and $8^{\circ} \mathrm{C}$.

In order to bring the biopreservative technology to a stage where it can become available for the CSS industry, it is necessary to evaluate the effect of the Carnobacterium strains on the quality of CSS. It has been clearly stated that the early quality deterioration of vacuum-packed CSS during vacuum storage at chilled temperature, resulting in the occurrence of off-odours and pasty textures (Stohr et al., 2001), is due to microbial activity (Joffraud et al., 1998). However, spoilage mechanisms are still incompletely understood. Several authors have identified the CSS microflora (Truelstrup Hansen et al., 1998; Stohr et al., 2001) which is highly variable both qualitatively and quantitatively due to difference in the final product composition and in hygienic conditions in the smokehouses (Truelstrup Hansen and Huss, 1998; Leroi et al., 2001). Just after the process, the microflora is often composed of a mixture of Gram-negative marine bacteria such as Shewanella putrefaciens, Photobacterium phosphoreum, Vibrio spp. and psychrotrophic Enterobacteriaceae (Truelstrup Hansen et al., 1995; Leroi et al., 1998; Jorgensen et al., 2000a). During the vacuum storage at refrigerated temperatures, Gram-positive bacteria especially lactic acid bacteria (LAB), represented by Lactobacillus spp. and Carnobacterium spp. become by far the most common variety (Truelstrup Hansen and Huss, 1998; Leroi et al., 1998). Brochothrix thermosphacta and yeasts can also be found in CSS but generally at lower level (Leroi et al., 2001). When inoculated in pure culture in sterile cold-smoked blocks, those micro-organisms do not all participate in spoilage. Lb. sakei, B. thermosphacta, Serratia liquefaciens and $P$. phosphoreum have been shown to be responsible of off-odours whereas the spoilage potential of C. piscicola is promisingly weak depending on the strain tested (Stohr et al., 2001). 
The aim of the present study was to evaluate the effect of three biopreservative Carnobacterium strains showing a high inhibition potential of $L$. monocytogenes (Brillet et al., 2004) on microbiological, chemical and sensory quality of CSS. First, the spoilage potential of C. divergens V41, C. piscicola V1 and C. piscicola SF668, was studied on a sterile CSS system by sensory evaluation of off-odour production and analysis of some physico-chemical indices. Following experiments one of the strains, C. divergens V41, was sprayed on slices of commercial CSS batches freshly processed, provided by four different French producers. The effect of inoculation on the sensory characteristics (odour, flavour, texture and colour), physico-chemical parameters ( $\mathrm{pH}, \mathrm{TVBN}$, biogenic amines) and natural microflora was evaluated during the four weeks of storage at refrigerated temperature.

\section{Materials and methods}

\subsection{Bacterial strains and subcultures conditions}

C. divergens V41 and C. piscicola V1 were isolated from salmon and trout intestine respectively and characterized by Pilet et al. (1995). C. piscicola SF668 was isolated from commercial Norwegian CSS by Leroi et al. (1998), and studied by Duffes et al. (1999b). All strains were stored at $-80^{\circ} \mathrm{C}$ in their growth medium with $20 \%(\mathrm{v} / \mathrm{v})$ sterile glycerol.

Elliker broth (BK 054, Biokar Diagnostics, Beauvais, France) was used as subculture medium to cultivate the Carnobacterium strains for $24 \mathrm{~h}$ at $20^{\circ} \mathrm{C}$ before inoculation in sterile CSS. As commercial CSS inoculated with C. divergens V41 was eaten by the panellists for sensorial analysis, the broth used to cultivate $C$. divergens V41 before inoculation was prepared without protein of animal origin, and contained wheat trypton $\left(20 \mathrm{~g} \mathrm{~L}^{-1}\right)$, glucose $(5$ $\left.\mathrm{g} \mathrm{L}^{-1}\right)$, saccharose $\left(5 \mathrm{~g} \mathrm{~L}^{-1}\right)$, yeast extract $\left(5 \mathrm{~g} \mathrm{~L}^{-1}\right), \mathrm{NaCl}\left(4 \mathrm{~g} \mathrm{~L}^{-1}\right)$, ascorbic acid $\left(0.5 \mathrm{~g} \mathrm{~L}^{-1}\right)$, $\mathrm{MgSO}_{4}\left(0.4 \mathrm{~g} \mathrm{~L}^{-1}\right), \mathrm{MnSO}_{4}\left(0.1 \mathrm{~g} \mathrm{~L}^{-1}\right)$. This medium was named WAP (Without Animal Protein) broth.

\subsection{Cold-smoked salmon}

Sterile CSS blocks were prepared as described by Joffraud et al. (1998) and modified by Brillet et al. (2004), from five Norwegian farmed salmon (Salmo salar) of approximately 4-5 kg, processed at IFREMER. Vacuum-packed bags of $300 \mathrm{~g}$ of CSS blocks were sterilised under frozen conditions $\left(-80^{\circ} \mathrm{C}\right)$ by ionising treatment at $1.2 \mathrm{kGy}$ (Gradient Ouest, Berric, France). Bags were stored frozen until inoculation.

The commercial salmons (Norwegian farmed Salmo salar), traditionally processed (dry-salting, traditional smoking with smoke from beech and oak shaving combustion), were provided by four different French CSS producers. Each batch, at least constituted of 10 fillets, was freshly processed, sliced in constant $40 \mathrm{~g}$ weight slices and vacuum-packed just before conveying in refrigerated conditions at our laboratory. Sliced fillets were stored at $4^{\circ} \mathrm{C}$ just after reception and slices were inoculated in the following hours.

\subsection{Sample preparation and storage}

\subsubsection{Sterile CSS blocks}

Cultures of C. divergens V41, C. piscicola V1 and SF668 were carried out twice successively in 10 and then $100 \mathrm{ml}$ of Elliker broth for $24 \mathrm{~h}$ at $20^{\circ}$ before cells were centrifuged and washed in sterile saline water $(\mathrm{NaCl}: 0.85 \% \mathrm{w} / \mathrm{v})$. Immediately, appropriate dilutions of Carnobacterium strains were inoculated separately $(2 \% \mathrm{v} / \mathrm{w})$ in 15 replicate 
samples of $50 \mathrm{~g}$ (for microbial and chemical analysis) and 28 samples of $20 \mathrm{~g}$ (for sensory analysis) of thawed sterile CSS blocks distributed in polyamide polyethylene bags (Bourdeau, St Etienne de Montluc, France). Pieces were gently mixed with the inoculating solution and samples were then vacuum-packed and incubated for 28 days using the following conditions : nine days at $4^{\circ} \mathrm{C}$ followed by 19 days at $8^{\circ} \mathrm{C}$ as specified in the French standard for shelf-life validation of perishable and refrigerated food (NF V 01-003, 2004) with a break during $2 \mathrm{~h}$ at $20^{\circ} \mathrm{C}$ after 19 days of storage (industrial recommendations). The initial desired level in the flesh for Carnobacterium spp. was $10^{5} \mathrm{CFU} \mathrm{\textrm {g } ^ { - 1 }}$. A control made of CSS blocks inoculated with $2 \%$ of sterile saline was also prepared.

\subsubsection{Commercial CSS slices}

Cultures of $C$. divergens V41 were carried out twice successively in 10 and then 100 $\mathrm{ml}$ of WAP broth for $24 \mathrm{~h}$ at $20^{\circ} \mathrm{C}$ and cultures were washed as previously described for sterile CSS experiments. Immediately, appropriate dilution of $C$. divergens V41 was aseptically sprayed $(1 \% \mathrm{v} / \mathrm{w})$ on each side of 70 slices per batch of commercial CSS with an aerographer (Paasches V, Paasche Airbrush Company, Illinois, USA). Slices were sprayed in a laminar flow hood. Slices were then aseptically installed on carbon tray (two slices per tray) and vacuum-packed in bags provided by each producer, to be in the same packing conditions as in supermarkets. The initial desired level in the flesh for $C$. divergens V41 was $10^{5} \mathrm{CFU} \mathrm{g}$ 1 . For each batch, a control was made of 70 slices packed in the same fashion as inoculated samples but without spraying saline, to be exactly as in commercial processing conditions. Samples and controls were stored for 28 days in the conditions previously described for sterile CSS experiments.

\subsection{Microbiological analysis}

For both inoculated CSS blocks and commercial slices, microbial analysis was done weekly in triplicate samples. Salmon samples $(30 \mathrm{~g})$ were homogenised and diluted in $120 \mathrm{ml}$ chilled physiological saline containing $0.85 \%(\mathrm{w} / \mathrm{v}) \mathrm{NaCl}$ and $0.1 \%(\mathrm{w} / \mathrm{v})$ tryptone (Biokar Diagnostics) for $2 \mathrm{~min}$ in a stomacher (Lab. Blender, London, UK). After $30 \mathrm{~min}$ at room temperature, the homogenate was 10-fold serially diluted in physiological saline, and $0.1 \mathrm{ml}$ or $1 \mathrm{ml}$ of each appropriate dilution was spread-plated or pour-plated respectively in duplicate. For commercial CSS slices, total viable counts (TVC), total LAB, lactobacilli, Enterobacteriaceae, B. thermosphacta and yeasts were enumerated with appropriate agar medium and incubation conditions, as described by Cardinal et al. (2004). Listeria spp. was enumerated in pour plates of Palcam agar (BK145, Biokar Diagnostics) with selective supplement (BS00408, Biokar Diagnostics). Plates were incubated at $30^{\circ} \mathrm{C}$ for 48 hours. In order to lower the threshold to one Listeria spp. per gram, five Palcam plates per sample were inoculated. For CSS inoculated blocks, only total LAB were enumerated, corresponding to the inoculated carnobacteria.

\subsection{Chemical analysis}

For both inoculated blocks and commercial CSS, $200 \mathrm{~g}$ of flesh were sampled just after processing, and homogenised in a Warring Blender. Dry matter content was analysed by oven drying $10 \mathrm{~g}$ of homogenate smoked salmon at $103^{\circ} \mathrm{C}$ until reaching a constant weight. Total fat content was determined by hexane extraction, and sodium chloride content was measured with a Chloride Analyser 926 (Corning, Halstead, England). Total phenols were quantified by the colorimetric method described by Cardinal et al. (2004). 
Each week during storage, the remaining flesh in each package opened for microbiological analysis was homogenised in a Warning Blender. TVBN was determined in duplicate by the Conway micro-diffusion method (Conway and Byrne, 1933). The pH was measured in the homogenate of CSS used for microbiological analysis with a $\mathrm{pH}$-meter (Mettler Delta 320, AES, Combourg, France.

\subsection{Bacteriocin activity}

For all samples (both inoculated CSS blocks and commercial slices) $1 \mathrm{ml}$ of the fivefold dilution flesh was heated for $15 \mathrm{~min}$ at $80^{\circ} \mathrm{C}$ to inactivate protease and was stored at $80^{\circ} \mathrm{C}$ until used. Bacteriocin concentration was semi quantified against L. monocytogenes RF76 target strain (IFREMER collection) by a standardised agar diffusion test with critical dilution assay (Connil et al., 2002).

\subsection{Biogenic amines}

Another fraction of $1 \mathrm{ml}$ of the five-fold dilution flesh was kept at $-80^{\circ} \mathrm{C}$ for biogenic amines analysis (tyramine, histamine, cadaverine and putrescine). According to Eerola et al. (1993), quantification of biogenic amines requires a step of derivatization of sample extract. The protocol has been modified as follow : $100 \mu \mathrm{l}$ of $\mathrm{NaOH}(2 \mathrm{~N})$ were added to $300 \mu \mathrm{l}$ of thawed-homogenate of CSS. Next, $150 \mu \mathrm{l}$ of saturated sodium bicarbonate were added, followed by $1 \mathrm{ml}$ of freshly prepared dansyl chloride solution (10 $\mathrm{mg}$ dansyl chloride (Sigma Aldrich, L'Isle d'Abeau Chesnes, France) in $1 \mathrm{ml}$ of acetone. Reaction mixture was incubated at $40^{\circ} \mathrm{C}$ during $45 \mathrm{~min}$ safe from the light. Then, residual dansyl chloride was removed by adding $50 \mu \mathrm{l}$ ammonia. After $30 \mathrm{~min}$ in darkness, $700 \mu \mathrm{l}$ of acetonitrile were added, and reaction mixture was centrifuged $10 \mathrm{~min}$ at $4000 \mathrm{~g}$. Finally, supernatant was collected in glass tube and stored at $-20^{\circ} \mathrm{C}$ before analysis. Dansylated amines in homogenate of CSS were then separated by reversed-phase liquid chromatography (Eerola et al., 1993) on a C18 ODS2 Equisorb column $(4.6 \times 250 \mathrm{~mm}$, particle size $5 \mu \mathrm{m}$, CIL Cluzeau, France) mounted with a C18 Bondapack guard column (Waters, France) with a HPLC apparatus (Waters 600E Multisolvent Delivery System and Waters 2487 Dual $\lambda$ Absorbance Detector, Waters, France). The gradient elution was carried out with eluent A (ammonium acetate, $0.1 \mathrm{~mol} \mathrm{l}^{-1}$ ) and eluent B (acetonitrile) as describe by Connil et al. (2002). Dansylated amines were detected by u.v. absorption at $254 \mathrm{~nm}$ and their concentrations in each homogenate of CSS were calculated by a calibration curve for each amine (Borwin software).

\subsection{Sensory analysis}

The method used was a quantitative descriptive analysis with conventional profiling performed by an internal regularly trained panel of 14 people (IFREMER). Panellists were required to make a comparative evaluation of the products by scoring each descriptor on an unstructured line scale from zero (low intensity) to ten (high intensity). For CSS blocks, the four samples (three inoculated batches with different Carnobacterium spp. and control) were evaluated in one session. Nineteen odour descriptors were quoted after one and three weeks of storage, using $20 \mathrm{~g}$ of blocks per panellist. For commercial CSS slices, 34 sensory attributes (odour, appearance, flavour and texture) were weekly scored by the panel. Two sessions per week were necessary to evaluate all the samples (two commercial batches inoculated with $C$. divergens V41 and their control per session). The day of analysis, each package was opened and slices were cut in two portions individually repacked in aluminium foils. The main relevant and discriminative descriptors of smoked salmon slices were : odour : global 
intensity, smoke, raw salmon, herring, amine, acid, green aroma, rancid, ham, plastic, fruity, sour, butter, rubber, cheese, musty, hydrogen sulphide, cabbage, feacal ; appearance : pink colour, orange colour, homogeneity of colour ; flavour : global intensity, smoke, raw salmon, herring, rancid, salty taste, acid, amine, rubber ; texture : firmness, melting texture, pasty texture.

Another objective of the sensory evaluation was to assess the sensory rejection time. Samples were scored by the same 14 trained panellists who classified them into the following three classes defined by spoilage level on the basis of odour, flavour, texture and colour evaluation : class 1 , no spoilage noted, class 2 : weak spoilage, class 3 : strong spoilage. A quality coefficient (QC) was calculated as follow (Leroi et al., 2001): $\mathrm{QC}=[(1 \mathrm{x} \%$ class 1$)+$ $(2 \times \%$ class 2$)+(3 \times \%$ class 3$)] / 100$. A sample was rejected when QC was higher than 2, corresponding to sample scored in class 3 by at least $50 \%$ of the panellists.

\subsection{Statistical analysis}

Results are expressed as mean of three measures $\pm 95 \%$ Confidence Interval $(\mathrm{CI}=$ $1.96 \times \sqrt{\text { standard deviation } 2 / 3_{3}}$ ). For microbial and chemical data, means were compared by one-way analysis of variance with the least significance difference (LSD) test at the 0.05 level of probability (Statgraphics Plus, version 4, Sigma Plus). For CSS blocks, results of the sensory profiling test were treated by two-way analysis of variance (ANOVA) to test the effect of the carnobacteria strains and panellists with Fizz 2.00 software (Fizz system, Biosystèmes, Dijon, France). In case where significant differences occurred, the means were compared by the Duncan test at the 0.05 level of probability. For each batch of commercial CSS, slices inoculated with C. divergens V41 were compared to their respective control. Score for each descriptor was compared using a paired-sample Student test (Fizz system).

\section{Results}

\subsection{Effect of Carnobacterium spp. in sterile CSS blocks}

The salt and total phenol concentrations of CSS blocks used in these experiments were respectively $3.2 \%(\mathrm{w} / \mathrm{w}$, total phase) corresponding to $5.0 \%(\mathrm{w} / \mathrm{w}$, water phase) and $1.33 \mathrm{mg}$ $100 \mathrm{~g}^{-1}$. Dry matter and total fat content were $40.1 \%(\mathrm{w} / \mathrm{w})$ and $15.1 \%(\mathrm{w} / \mathrm{w})$ respectively.

Fig. 1 represents growth of the three carnobacteria in inoculated CSS during the four weeks of vacuum storage at chilled temperature. All strains grew in CSS blocks. For the two C. piscicola strains, growth curves were similar during the first three weeks but final count was slightly higher for $C$. piscicola V1 than for C. piscicola SF668 $\left(5.9 \pm 7.2 \times 10^{6}\right.$ and $8.7 \pm$ $3.6 \times 10^{5} \mathrm{CFU} \mathrm{g}^{-1}$ respectively). For $C$. divergens $\mathrm{V} 41$, although the initial inoculation level was lower by approximately $1 \log _{10}\left(\mathrm{CFU} \mathrm{g} \mathrm{g}^{-1}\right)$, the growth increased considerably at $8^{\circ} \mathrm{C}$ and this strain reached $7.4 \pm 3.1 \times 10^{6} \mathrm{CFU} \mathrm{g}^{-1}$ at the end of storage. 
Fig. 1 Growth of Carnobacterium divergens V41 (•), Carnobacterium piscicola SF668 (•) and Carnobacterium piscicola V1 ( $\mathbf{\Delta})$ in sterile cold-smoked salmon blocks during vacuum storage at 4 and $8^{\circ} \mathrm{C}$. Each growth curve represents the mean of three enumerations (bars : $95 \%$ confidence interval).

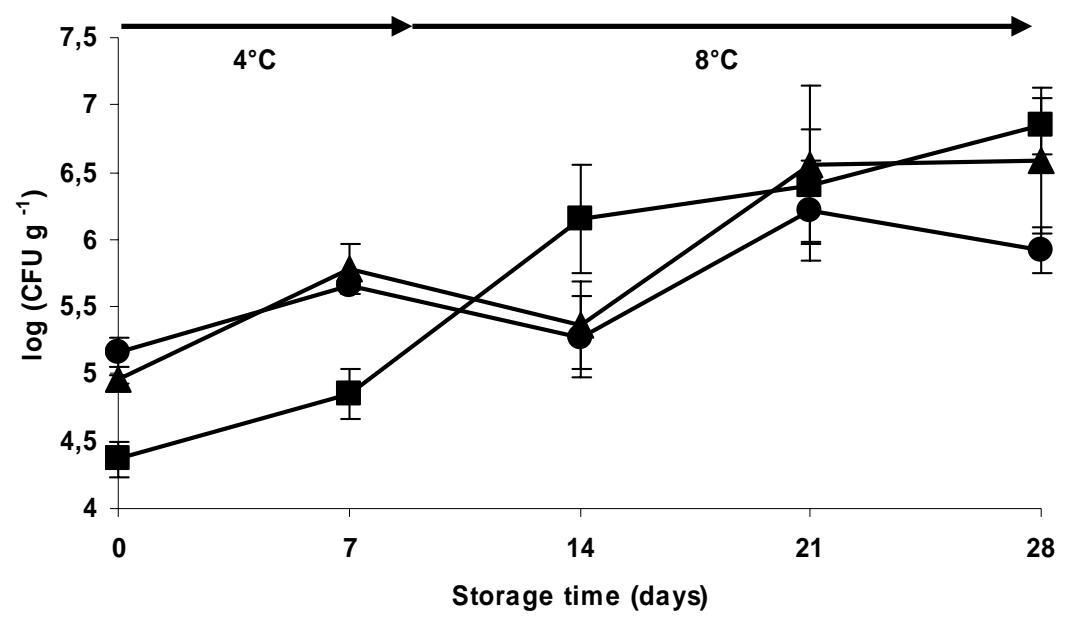

No TVBN was produced in CSS blocks, both in control and in inoculated samples. The average initial concentration was $13.3 \pm 0.9 \mathrm{mg}-\mathrm{N} 100 \mathrm{~g}^{-1}$ and remained stable (data not shown) during the four weeks of storage whatever the Carnobacterium strain considered (the average concentration was $15.3 \pm 1.7 \mathrm{mg}-\mathrm{N} 100 \mathrm{~g}^{-1}$ at the end of experiment). The $\mathrm{pH}$ was constant ranging between 5.95 and $6.03 \pm 0.02$ during the four weeks of storage and was not significantly different in control and inoculated samples (data not shown). Bacteriocin was never detected by the agar diffusion test.

Fig. 2 shows biogenic amines production in CSS blocks in presence of each Carnobacterium strain after four weeks of storage. The three carnobacteria strains produced tyramine, C. divergens V41 being the most important producer with $122 \pm 9 \mu \mathrm{g} \mathrm{g}^{-1}$ of tyramine after four weeks. C. piscicola SF668 and V1 produced two to four times less tyramine concentrations, with $63 \pm 8$ and $37 \pm 21 \mu \mathrm{g} \mathrm{g}^{-1}$ respectively. None of the carnobacteria produced histamine, putrescine nor cadaverine. 
Fig. 2 Biogenic amines concentration after four weeks of storage (nine days at $4^{\circ} \mathrm{C}$ and 19 at $8^{\circ} \mathrm{C}$ ) in sterile cold-smoked salmon blocks (control) and in inoculated blocks with Carnobacterium divergens V41, Carnobacterium piscicola SF668 and V1 (bars : 95\% confidence intervals).

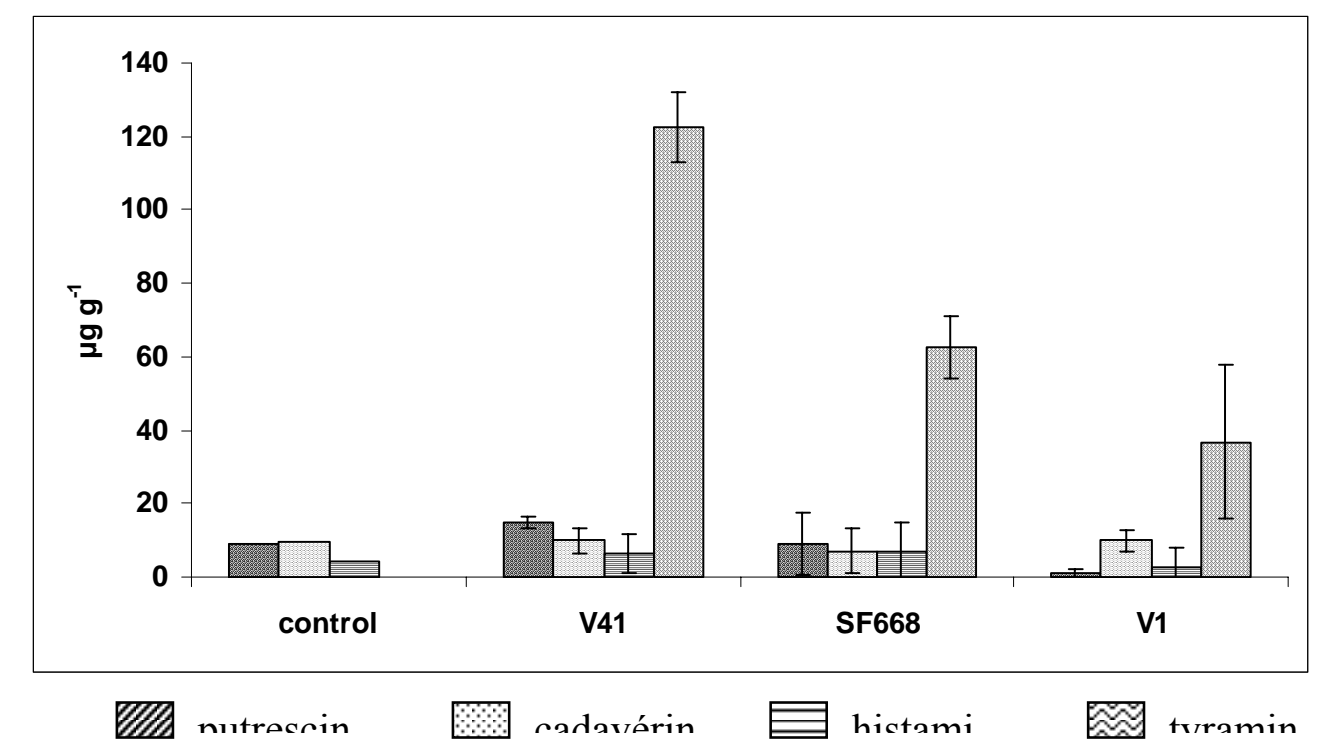

After one week of storage, no significant difference between control and inoculated samples was observed for any of the nineteen sensory descriptors quoted and samples were always considered as not spoiled (data not shown). Same results were observed after three weeks of storage, except a slight but significant note of cheese/feet detected in samples inoculated with $C$. divergens V41. However, the average score of the 14 panellists for this descriptor was very low ( 0.6 on a scale ranging from 0 to 10$)$.

\subsection{Effect of C. divergens V41 in commercial CSS slices}

In the first part of this study, no significant difference was observed between the three strains of carnobacteria concerning their spoilage potential in CSS. As C. divergens V41 had showed the highest inhibition capacity against a wide collection of $L$. monocytogenes (Brillet et al., 2004), this strain was selected for an application in naturally contaminated CSS slices. Chemical composition of each CSS batch is shown in Table 1. A wide variation among batches was noticed but all results satisfied with the French CSS standard (NF V 45-065, 1997). 
Table 1 Chemicals analyses of the four commercial cold-smoked salmon (CSS) batches

\begin{tabular}{|c|c|c|c|c|}
\hline CSS batches & $\begin{array}{l}\text { sodium chloride } \\
(\% \mathrm{w} / \mathrm{w} \mathrm{WP})^{*}\end{array}$ & $\begin{array}{l}\text { total phenols } \\
\left(\mathrm{mg} 100 \mathrm{~g}^{-1}\right)\end{array}$ & $\begin{array}{l}\text { dry matter } \\
(\% \mathrm{w} / \mathrm{w})\end{array}$ & $\begin{array}{l}\text { total fat } \\
(\% \mathrm{w} / \mathrm{w})\end{array}$ \\
\hline A & 5.0 & 0.47 & 35.7 & 8.4 \\
\hline B & 4.6 & 0.68 & 38.8 & 11.8 \\
\hline $\mathrm{C}$ & 3.8 & 0.85 & 40.6 & 15.4 \\
\hline D & 5.6 & 0.93 & 41.7 & 14.6 \\
\hline
\end{tabular}

*WP : in water phase $=\% \mathrm{NaCl}(\mathrm{w} / \mathrm{w}$ in CSS) $\times 100 / \% \mathrm{NaCl}(\mathrm{w} / \mathrm{w}$ in CSS $)+\%$ water in CSS

\subsubsection{Effect of C. divergens V41 on microbiology}

Just after reception, natural microflora of CSS was very different from one batch to another and two cases were observed : two batches (smokehouses A and D) were of high hygienic quality whereas two other batches (B and C) were strongly contaminated. In the first case (A and D), just after processing and reception of the batches at the laboratory, TVC was below the detection threshold $\left(25 \mathrm{CFU} \mathrm{\textrm {g } ^ { - 1 }}\right)$. In the control $\mathrm{A}$, the microflora increased gradually to reach around $10^{5} \mathrm{CFU} \mathrm{g}{ }^{-1}$ at the end of storage and was composed of a mixture of Enterobacteriaceae, yeasts and LAB partially represented by Lactobacillus (Fig. 3a). No B. thermosphacta nor Listeria spp. was detected on the plates. In the control D after four weeks of storage, a surprisingly very weak growth of the initial microflora was observed (data not shown) ; TVC never exceeded $10^{2} \mathrm{CFU} \mathrm{g^{-1 }}$ and was represented by LAB probably belonging to the Carnobacterium specie (no count on Rogosa agar). When C. divergens V41 was sprayed on batches A and D, TVC was only represented by the inoculated bacterium which grew from $10^{4-5}$ to $10^{7-8} \mathrm{CFU} \mathrm{g}{ }^{-1}$ in three weeks. The other groups of flora were slightly inhibited by presence of $C$. divergens V41 (Fig. 3b). Average counts of Enterobacteriaceae, Lactobacilli and yeasts never exceeded $4 \times 10^{2}, 3 \times 10^{2}$ and $2 \times 10^{2} \mathrm{CFU} \mathrm{g}^{-1}$ whereas they reached $6 \times 10^{4}, 7 \times 10^{2}$ and $2 \times 10^{4} \mathrm{CFU} \mathrm{g}^{-1}$ in control. However, due to high heterogeneity in naturally contaminating flora within packages, differences between control and inoculated samples were not statistically significant.

In the second case (strongly spoiled CSS), TVC at the beginning of the storage was around $10^{5} \mathrm{CFU} \mathrm{g}{ }^{-1}$ and was probably dominated by marine gram-negative bacteria such as Photobacterium spp., Vibrio spp., Shewanella spp. or Pseudomonas spp.. TVC increased rapidly in both controls $\mathrm{B}$ and $\mathrm{C}$ and reached their maximum level $\left(10^{7-8} \mathrm{CFU} \mathrm{g} \mathrm{g}^{-1}\right)$ after one and three weeks respectively. $\mathrm{LAB}$, mainly represented by lactobacilli, became rapidly the dominating flora but Enterobacteriaceae, Brochothrix thermosphacta and yeasts were also

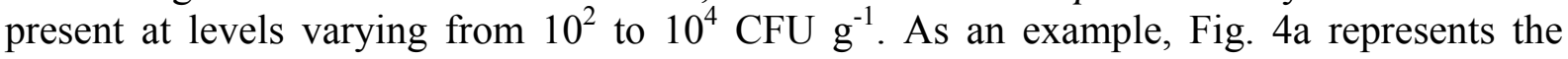
evolution of naturally contaminating microflora of CSS for batch C. Listeria spp were also detected in this batch, at a level never exceeding $8 \mathrm{CFU} \mathrm{g}^{-1}$, whereas in batch $\mathrm{B}$, no colony was detected on Palcam plates. When $C$. divergens V41 was sprayed on batches B and $\mathrm{C}$, the inoculated $\mathrm{LAB}$ represented the dominating flora during the first two weeks. However, it rapidly became difficult to distinguish the inoculated bacteria from the natural LAB contaminating slices because the level of LAB in control was the same as in inoculated samples (Fig. 4b). No statistical reduction of the average count of the spoiling microflora was observed, for both batch B and C during the four weeks storage period. Count of Listeria spp. in batch $\mathrm{C}$ was lowered $\left(<1 \mathrm{CFU} \mathrm{g}^{-1}\right.$ after three and four weeks of storage) but inhibition was not significant due to very low level of contamination in control. 
Fig. 3 Growth of natural microflora (batch A) in control (a) and in the presence of $C$. divergens V41 (b) during vacuum storage at $4^{\circ} \mathrm{C}$ for nine days and $8^{\circ} \mathrm{C}$ for 19 days : $(\diamond)$ total viable count, $(\square)$ lactic acid bacteria, $(\Delta)$ Lactobacillus spp., $(*)$ Enterobacteriaceae, ( $(\circ)$ yeast. Neither Listeria spp. nor Brochothrix thermosphacta were detected. Each growth curve represents the mean of three enumerations.
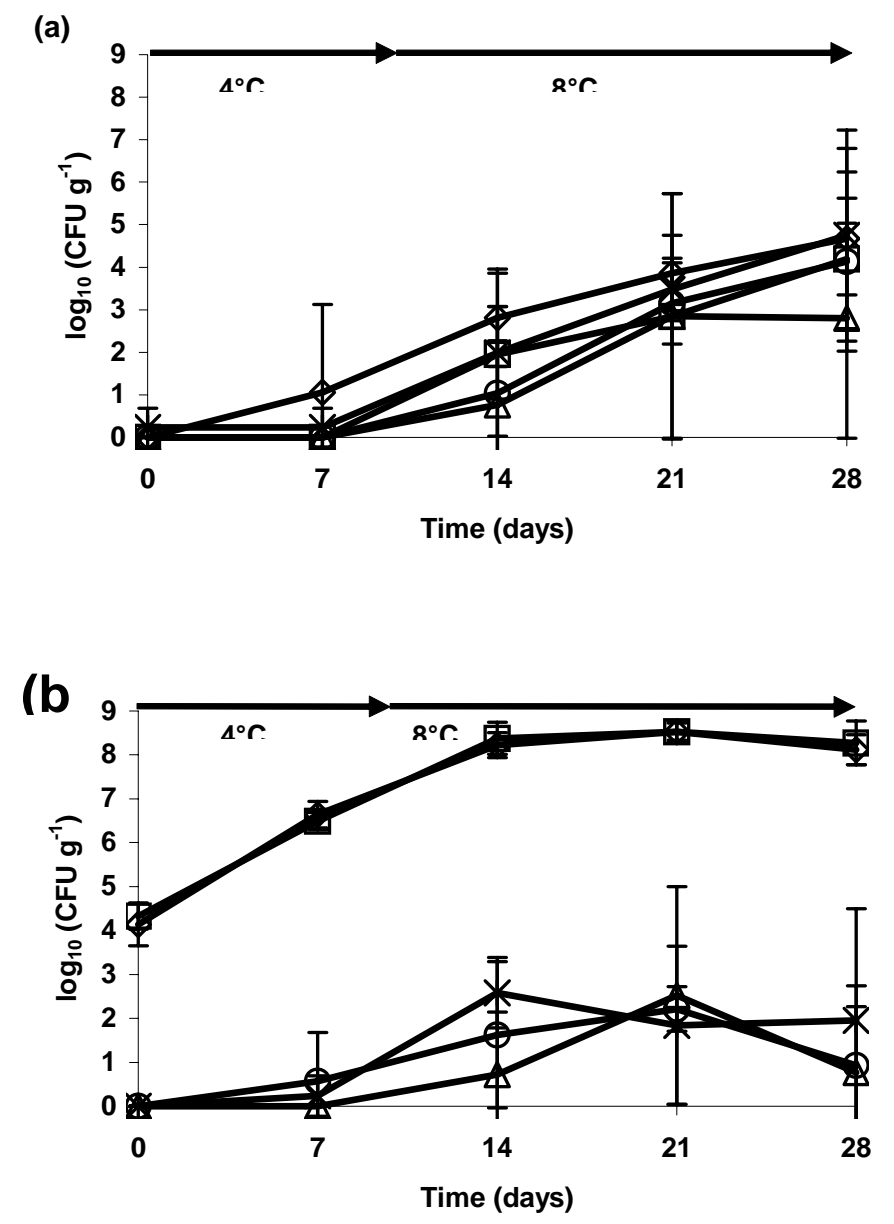

\subsubsection{Effect of C. divergens V41 on physico-chemical parameters}

All over the storage, the $\mathrm{pH}$ was rather stable in controls and in batches inoculated with C. divergens V41, ranging between 5.9 to 6.2, and no statistical difference was observed between samples. Results for TVBN production are shown in Table 2. In the first case (smokehouses $\mathrm{A}$ and $\mathrm{D}$, high hygienic quality) no TVBN was produced, TVBN concentration

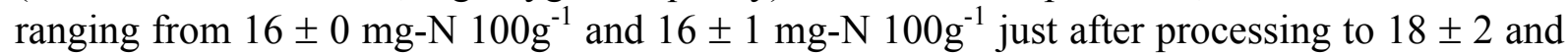
$21 \pm 2 \mathrm{mg}-\mathrm{N} 100 \mathrm{~g}^{-1}$ in samples A and D respectively, after four weeks of storage. In the presence of $C$. divergens V41, TVBN production was slightly but significantly increased with $29 \pm 0$ and $25 \pm 2 \mathrm{mg}-\mathrm{N} 100 \mathrm{~g}^{-1}$ after 4 weeks for samples A and D respectively. In the second case (smokehouses $\mathrm{B}$ and $\mathrm{C}$, poor hygienic quality), important TVBN production was noticed in control (42 \pm 2 and $51 \pm 9 \mathrm{mg}-\mathrm{N} 100 \mathrm{~g}^{-1}$ respectively, at the end of experiment) and there was no significant difference with inoculated samples $\left(45 \pm 1\right.$ and $50 \pm 9 \mathrm{mg}-\mathrm{N} 100 \mathrm{~g}^{-1}$ respectively). 
Fig. 4 Growth of natural microflora (batch $C$ ) in control (a) and in the presence of $C$. divergens V41 (b) during vacuum storage at $4^{\circ} \mathrm{C}$ for nine days and $8^{\circ} \mathrm{C}$ for 19 days : $(\diamond)$ total viable count, $(\square)$ lactic acid bacteria, $(\Delta)$ Lactobacillus, $\left(^{*}\right)$ Enterobacteriaceae, $(\circ)$ yeast, $(\times)$ Listeria spp., (+) Brochothrix thermosphacta. Each growth curve represents the mean of three enumerations.
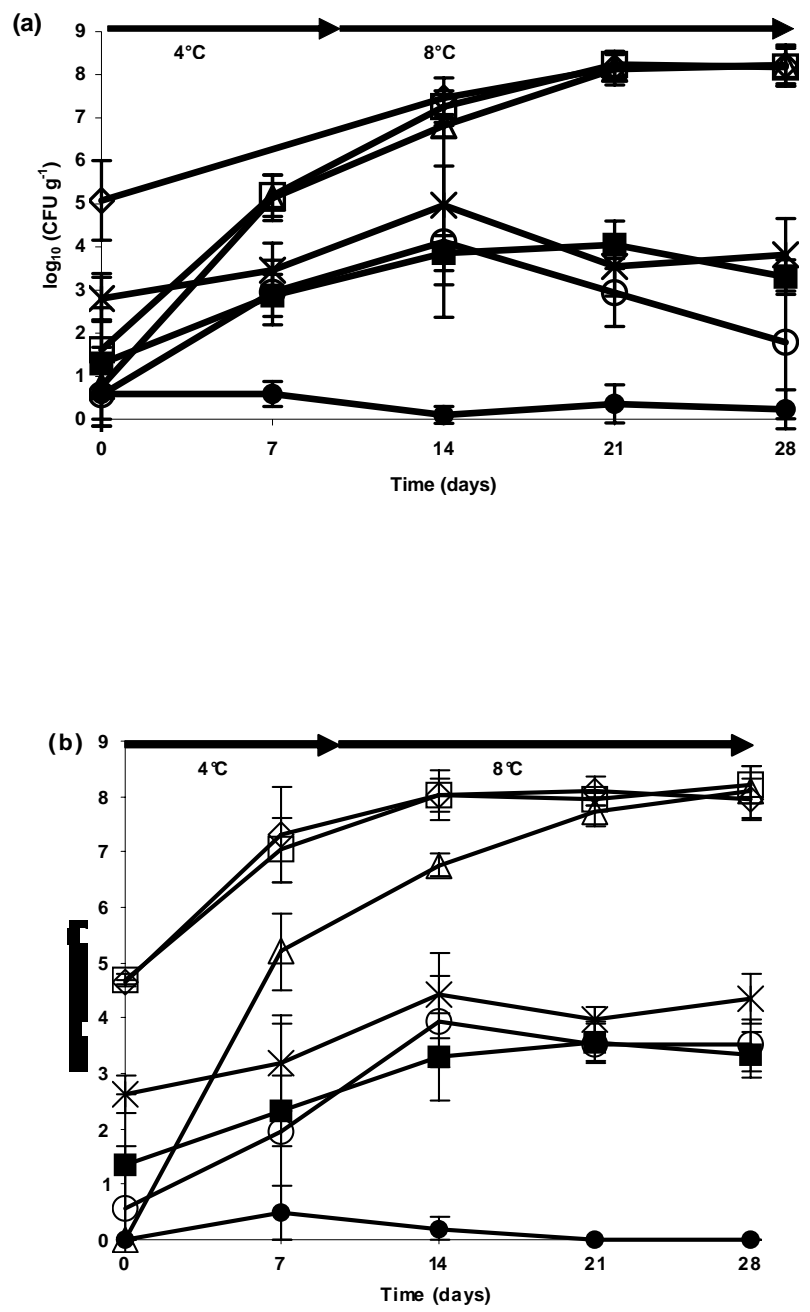

No bacteriocin activity was detected during storage by agar diffusion test, both for control and inoculated samples.

The concentration of putrecine, cadaverine, histamine and tyramine produced during the storage is shown in Fig. 5 for batch A and C. In weakly spoiled CSS (batches A), no biogenic amine was detected except a weak quantity of putrecine and cadaverine in control (Fig. 5a) at the end of storage ( $10 \pm 5$ and $28 \pm 9 \mu \mathrm{g} \mathrm{g}^{-1}$ respectively). In the presence of $C$. divergens $\mathrm{V} 41$, tyramine was produced ( $372 \pm 3 \mu \mathrm{g} \mathrm{g}^{-1}$ after four weeks), as it had previously been observed in inoculated CSS blocks(Fig. 5b). In strongly spoiled CSS (batches B and C), biogenic amine were produced early during storage. As an example for batch $\mathrm{C}$ after two weeks, $689 \pm 140,147 \pm 110$ and $81 \pm 3 \mu \mathrm{g} \mathrm{g}^{-1}$ of cadaverine, histamine and tyramine were respectively produced, reaching $992 \pm 131,254 \pm 66$ and $226 \pm 61 \mu \mathrm{g} \mathrm{g}^{-1}$ after four weeks (Fig. 5c). In the presence of $C$. divergens V41, a slight inhibition was observed in cadaverine and histamine production after two weeks (respectively $235 \pm 322$ and $59 \pm 110 \mu \mathrm{g} \mathrm{g}^{-1}$ ) but similar concentrations were observed at the end of storage $\left(1050 \pm 295\right.$ and $231 \pm 216 \mu \mathrm{g} \mathrm{g}^{-1}$ respectively) (Fig. 5d). No significant difference between tyramine produced in naturally 
contaminated product (control) and products inoculated with $C$. divergens V41 was noticed (respectively $226 \pm 61$ and $251 \pm 38 \mu \mathrm{g} \mathrm{g}^{-1}$ at the end of experiment). Similar results were observed in batch B (data not shown), excepted a slight putrescine production detected in control and assay at the end of storage (respectively $70 \pm 130$ and $58 \pm 53 \mu \mathrm{g} \mathrm{g}^{-1}$ ).

Table 2 Total volatile basic nitrogen production $\left(\mathrm{mg}-\mathrm{N} 100 \mathrm{~g}^{-1}\right)$ in commercial batches of cold-smoked salmon alone and in presence of Carnobacterium divergens V41, stored under vacuum during nine days at 4 and 19 days $8^{\circ} \mathrm{C}$. Each result represents the mean of three measures ( $95 \%$ confidence interval).

\begin{tabular}{|c|c|c|c|c|c|c|}
\hline & & & & Time (week) & & \\
\hline & CSS batch & 0 & 1 & 2 & 3 & 4 \\
\hline \multirow{3}{*}{ A } & Control & $16.4( \pm 0.0)$ & $16.6( \pm 0.8)$ & $18.8( \pm 0.4)$ & $16.7( \pm 0.4)$ & $18.2( \pm 1.8)$ \\
\hline & & & & & & \\
\hline & C. divergens V41 & $17.6( \pm 0.2)$ & $17.2( \pm 0.9)$ & $20.6( \pm 1.0)$ & $24.7( \pm 1.9)$ & $28.8( \pm 0.0)$ \\
\hline \multirow{3}{*}{ B } & Control & $18.0( \pm 3.2)$ & $26.7( \pm 9.4)$ & $34.3( \pm 3.1)$ & $33.6( \pm 2.7)$ & $41.9( \pm 2.0)$ \\
\hline & & & & & & \\
\hline & C. divergens V41 & $19.5( \pm 4.3)$ & $32.3( \pm 1.7)$ & $38.1( \pm 3.7)$ & $39.5( \pm 1.1)$ & $44.8( \pm 0.6)$ \\
\hline \multirow{2}{*}{$\mathrm{C}$} & Control & $16.2( \pm 0.9)$ & $26.6( \pm 0.8)$ & $29.5( \pm 7.4)$ & $44.0( \pm 2.6)$ & $51.3( \pm 9.5)$ \\
\hline & C. divergens V41 & $15.0( \pm 0.8)$ & $20.6( \pm 6.8)$ & $28.2( \pm 6.8)$ & $40.4( \pm 1.9)$ & $49.6( \pm 8.6)$ \\
\hline \multirow{3}{*}{$\mathrm{D}$} & Control & $16.2( \pm 0.9)$ & $17.1( \pm 1.9)$ & $19.1( \pm 1.2)$ & $18.9( \pm 1.2)$ & $21.0( \pm 2.0)$ \\
\hline & & & & & & \\
\hline & C. divergens V41 & $15.9( \pm 1.1)$ & $17.0( \pm 1.3)$ & $19.4( \pm 2.6)$ & $27.4( \pm 1.5)$ & $25.0( \pm 2.2)$ \\
\hline
\end{tabular}


Fig. 5 Biogenic amines concentration in commercial CSS during vacuum storage at $4{ }^{\circ} \mathrm{C}$ for nine days and $8^{\circ} \mathrm{C}$ for 19 days : (a) batch A, control ; (b) batch A inoculated with Carnobacterium divergens V41, (c) batch C, control (d) batch $\mathrm{C}$ inoculated with Carnobacterium divergens V41 (bars : 95\% confidence intervals).
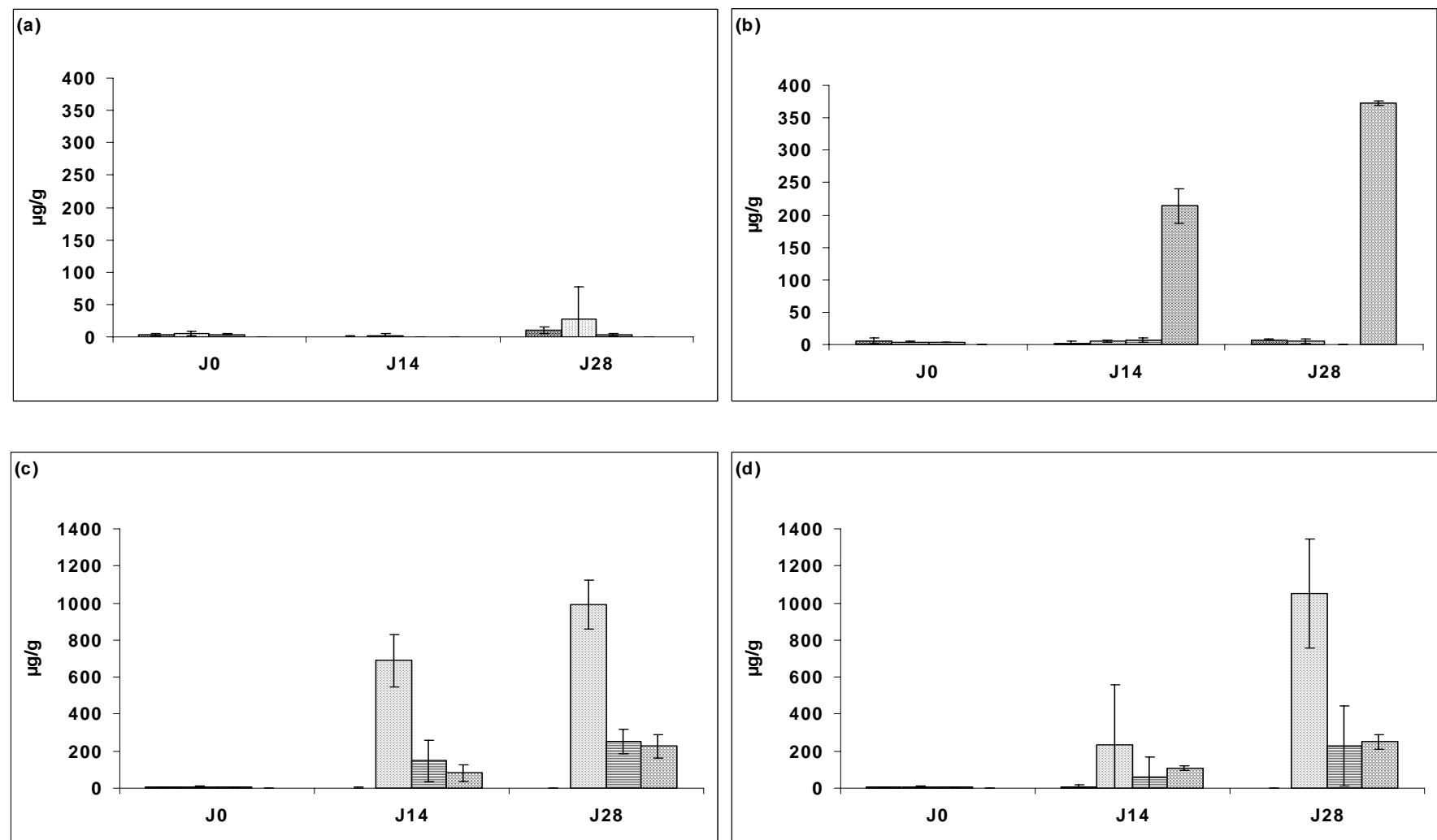

nutrescine

cadavérine

histamine

涂 tvramine

\subsubsection{Effect of C. divergens V41 on sensory quality}

Profiling sensory analysis were performed weekly on each batch of CSS (control and inoculated samples). In the first case (high hygienic quality, batches A and D), control were of very high sensory quality all over the storage, with no degradation of the initial score for the 34 descriptors. Statistical analysis at $95 \%$ level of confidence revealed very few difference between control and inoculated products for the descriptors of appearence, odour, flavour, and texture (data not shown). Inoculated products presented a slightly more intensive global and plastic odour, pink colour and firm texture but those differences were not observed regularly during storage. At $90 \%$ level of confidence, some odours such as sour, acid and feet and amine flavour were significantly higher in inoculated product than in control, but always with a very low score (less than one on a scale ranging between zero and ten). The quality coefficient (QC) resulting of classification in three spoiling classes is shown on Fig. 6. Results confirm that control A and D were of very high quality during the four weeks of storage (QC $=1$ ). Presence of $C$. divergens V41 was slightly detected by the trained panel after two to three weeks but QC remained always less than 1.5, which corresponds to products not or weakly spoiled. In the second case (batches B and C strongly spoiled) controls were rejected by the panel $(\mathrm{QC}>2)$ after 12 and 8 days respectively (Fig. 6). After three and two weeks for 
batches $\mathrm{B}$ and $\mathrm{C}$ respectively, panellists refused to eat sample and only scored odour and appearance descriptors. The main sensory descriptors highly scored for these batches were amine and, to a lesser extend, sour, acid, cabbage, rancid and feacal odours. Presence of $C$. divergens V41 was not detected by the panel, for both batches B and $\mathrm{C}$. There was no statistical difference between control and assays in any of the 34 sensory descriptors even at $90 \%$ level of confidence (data not shown) all over the storage period. Accordingly, low differences in QC between control and inoculated CSS slices were observed (Fig. 6).

Fig. 6 Quality coefficient for commercial cold-smoked salmon batches. Open symbol : control ; closed symbol : inoculated with Carobacterium divergens V41. Batch A ( $\square, \mathbf{\square})$, batch B $(\diamond, \diamond)$, batch $\mathrm{C}(\circ, \bullet)$, batch $\mathrm{D}(\Delta, \boldsymbol{\Delta})$.

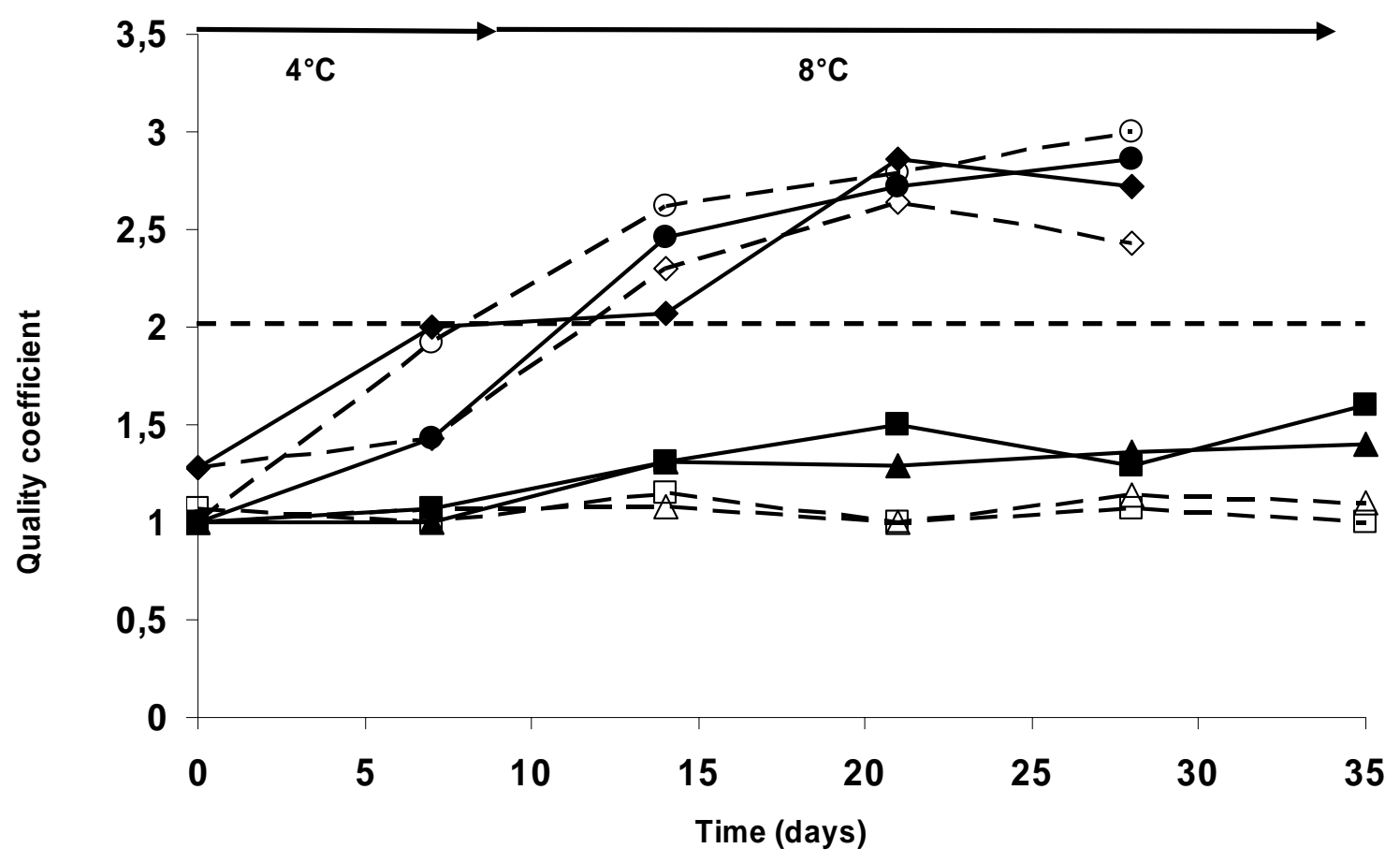

\section{Discussion}

A strategy of biopreservation of CSS against L. monocytogenes risk by the use LAB has been developed by Brillet et al. (2004). In order to allow implementation of this technology in the industry, the effect of the selected LAB on CSS quality had to be considered. The three Carnobacterium strains tested grew in inoculated CSS blocks, with a slight advantage for $C$. divergens V41. This result confirmed previous observations done by Brillet et al. (2004). However in the present study, final count of carnobacteria was always one to two $\log _{10}\left(\mathrm{CFU} \mathrm{g}{ }^{-1}\right)$ lower than in the former study. This could be explained by a higher level of total phenols in this experiment $\left(1.33 \mathrm{vs} 0.81 \mathrm{mg} 100 \mathrm{~g}^{-1}\right)$ (Thurette et al., 1998 ; Leroi et al., 2000), whereas salt concentrations were similar. No $\mathrm{pH}$ acidification was noticed in CSS blocks when inoculated with C. divergens V41, C. piscicola V1 and SF668, confirming the none aciduric status of carnobacteria. The three strains did not produce TVBN, which has been identified as one of the major quality index for CSS (Leroi et al., 2001). None of the three Carnobacterium showed any spoiling capacity according to the profiling test performed on odours by 14 trained panellists. These results are in agreement with previous works in which Carnobacterium spp. were not considered as specific spoilage organisms (Leroi et al., 1998; Joffraud et al., 2001; Stohr et al., 2001) and were probably not involved in 
CSS spoilage (Paludan-Muller et al., 1998). Vaz-Velho et al. (in press) also have shown that C. divergens V41 did not produced off-odour in cold-smoked trout.

Concerning safety aspects, none of the three strains tested were able to produce histamine which is regarded as the main agent for scombrotoxic fish poisoning (Taylor, 1986), nor putrecine and cadaverine, often correlated to spoilage (Jorgensen et al., 2000a). However, the three carnobacteria produced small amount of tyramine. Tyramine production by Carnobacterium spp. has already been observed by Edwards et al. (1987), Leisner et al. (1994) and Jorgensen et al. (2000b). In our set of experiments, C. divergens V41 was shown to be the greatest tyramine producer $\left(122 \mu \mathrm{g} \mathrm{g}^{-1}\right.$ vs 63 and $37 \mu \mathrm{g} \mathrm{g}^{-1}$ for C. piscicola SF668 and V1 respectively) but this concentration is to be related to the highest $C$. divergens V41 count at the end of the experiment. To correlate tyramine production with cell numbers during bacterial growth, the apparent yield factors for production of tyramine, $\mathrm{pY} \mathrm{Y}_{\mathrm{TYR} / \mathrm{CFU}}$, was calculated according to Jorgensen et al. (2000b). The $\mathrm{pY}_{\mathrm{TYR} / \mathrm{CFU}}$ values were $5.1 \pm 0.3,4.8 \pm$ 0.2 and $4.1 \pm 0.1$ respectively for C. piscicola V1, C. divergens V41 and C. piscicola SF668 showing that $C$. divergens V41 and $C$. piscicola V1 had a lower activity of tyramine production than $C$. piscicola SF668 (i.e., lower $\mathrm{pY}$ TYR/CFU value). Tyramine may cause migraine headaches and hypertensive effects, and in some cases can act as a potentiator of histamine effects (Ten Brink et al., 1990). However, tyramine concentration found in CSS blocks inoculated with $C$. divergens V41 is lower than natural tyramine concentrations currently reported in commercial CSS (Jorgensen et al., 2000b; Connil et al., 2002) and no legal upper limit exists for tyramine in fish products in the European legislation. Finally, $C$. divergens V41 have shown the highest $L$. monocytogenes inhibitory capability (Brillet et al., 2004) which lead us to select it for an application on naturally contaminated CSS slices.

As the microbial ecology of CSS is very complex and may vary among smokehouses (Leroi et al., 2001), potential application of biopreservation on commercial CSS was tested by spraying C. divergens V41 at a level of $10^{4-5} \mathrm{CFU} \mathrm{g}^{-1}$ on the slices of four batches provided by different smokehouses. According to several studies (Truelstrup Hansen and Huss, 1998; Leroi et al., 2001; Gram and Dalgaard, 2002; Cardinal et al., 2004), initial TVC just after processing were very heterogeneous, with two batches presenting a very good hygienic quality (TVC $<25 \mathrm{CFU} \mathrm{g}^{-1}$ ) and two batches being highly contaminated (TVC $>10^{4-5} \mathrm{CFU} \mathrm{\textrm {g } ^ { - }}$ 1 ).

On weakly spoiled CSS slices (batches A and D), C. divergens V41 grew very well, from $10^{4}$ to $10^{8} \mathrm{CFU} \mathrm{g}^{-1}$ in two weeks. Growth was more obvious than in inoculated CSS blocks, probably due to a lower total phenol concentrations in batches A and D (respectively

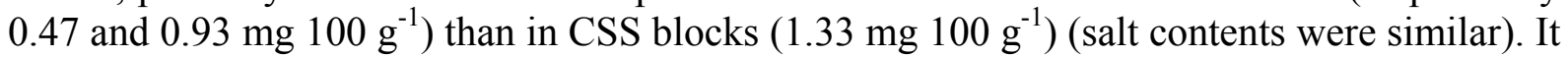
is also possible that bacterial growth on thin slices was enhanced compared with growth on blocks due to higher surface and nutrient availability. In the presence of C. divergens V41, growth of the different microflora specifically enumerated were slightly inhibited, but due to high heterogeneity of contamination of the slices inside a batch, those differences were not significant at the $95 \%$ probability level. Inhibition of lactobacilli could be explained by sensitivity of some Lactobacillus strains to divercin V41 produced by C. divergens V41 (Pilet et al., 1995). Inhibition of Enterobacteriaceae and yeasts could be due to nutrient competition but has not been further investigated. Concerning the TVBN production, an increase of around $10 \mathrm{mg}-\mathrm{N} 100 \mathrm{~g}^{-1}$ in samples containing the inoculated strain was observed in comparison with controls. This production had not been observed when C. divergens V41 was inoculated in CSS blocks, suggesting particular interaction between the LAB starter and the natural contaminating bacteria. For example, high level production of TVBN has been observed in sterile CSS blocks inoculated with co-culture of $C$. piscicola and $B$. thermosphacta while no production was noticed by any of the strains when inoculated in pure culture (unpublished data). Nevertheless, the level of TVBN at the end of storage was always 
lower than the $30 \mathrm{mg}-\mathrm{N} 100 \mathrm{~g}^{-1}$ spoilage limit defined by Leroi et al. (2001) for CSS. No production of biogenic amines was detected in the control whereas tyramine was produced in the samples inoculated with $C$. divergens V41 as it was expected. The amount of tyramine detected after four weeks of storage was three times higher than the amount measured in inoculated CSS, probably due to the high count of carnobacteria at the end of the storage. It is unlikely that production of tyramine by Carnobacterium was enhanced in the presence of indigenous flora as no particular metabolic interaction was detected when Carnobacterium spp. were co-inoculated with different species isolated from CSS (Jorgensen et al., 2000b). The final level of tyramine could be reduced by respecting the chilled storage temperature $\left(4^{\circ} \mathrm{C}\right)$. Indeed, Connil et al. (2002) have showed that tyramine production by $C$. divergens V41 was delayed at low temperatures. During the first two weeks of storage, no sensory difference between control and inoculated products was noticed. After that, trained panellists were able to discriminate the products, which is not really surprising because they compared CSS inoculated with high level C. divergens V41 to CSS which natural contamination do not contain many bacteria. Some slight off-odours and taste were detected but always at very low level (less than one on a scale from zero to ten whereas in highly spoiled batches B and C, those descriptors reach five or six) and products were never rejected by the panel until the end of storage.

On extensively spoiled CSS batches, all flora grew very quickly and reached their maximum level after two to three weeks. Batches B and $\mathrm{C}$ had a low level of salt (respectively 4.6 and $3.8 \%$ in WP) compared to batches A and D (5.0 and 5.6\% in WP), and were fairly smoked. As demonstrated by Leroi et al. (2000) these characteristics may explain the quicker growth of the natural microflora. LAB which were in the minority at the beginning quickly became dominant, and were represented mainly by lactobacilli (count on Rogosa agar at $\mathrm{pH}$ 5.5 identical to count on Nitrite Actidione Polymixine agar used for total LAB enumeration). This predominance has already been observed in several studies and specially at the end of the storage period (Leroi et al., 1998; Lyhs et al., 1998, Jorgensen et al., 2000a) probably because a lot of lactobacilli are well adapted to cold-smoked salmon condition, being psychrotrophic facultative anaerobic bacteria and able to grow in the presence of up to 8-10\% of $\mathrm{NaCl}$. Both controls from batch $\mathrm{B}$ and $\mathrm{C}$ were rejected by the panellists, after three and two weeks respectively, because of very strong amine off-odours. Those odours are clearly linked with the presence of lactobacilli at high levels. Although unspecifically identified in this study, $L b$. curvatus and $L b$. sakei species frequently dominate the LAB colonizing lightly preserved fish product (Leroi et al., 1998; Truelstrup Hansen and Huss, 1998; Lyhs et al., 1999, Jorgensen et al., 2000a). Lb. sakei was identified as a great spoilage organism in CSS and often releases strong sulphurous and acidic odours (Truelstrup Hansen et al., 1995; Stohr et al., 2001, Joffraud et al., 2001). Lb. curvatus was also identified as a specific spoilage organism of CSS because of its production of biogenic amines (Jorgensen et al., 2000b). It is also possible that psychrotrophic Enterobacteriaceae and B. thermosphacta, although present at a lower level, participate in spoilage because those micro-organisms can produce strong off-odours when inoculated in CSS blocks ( Joffraud et al., 2001; Stohr et al., 2001). In the presence of C. divergens V41, none of the natural flora enumerated were inhibited and grew as well as in the control. No difference in TVBN production was observed. However, after two weeks of storage, cadaverine and histamine concentrations were significantly reduced in inoculated products. This could be explained by an inhibition of strains from the Vibrionaceae family which are not specifically enumerated in this study. Indeed, Jorgensen et al. (2000b) have shown that $P$. phosphoreum was the only species isolated from CSS that produced histamine below $10^{\circ} \mathrm{C}$. This species also produced cadaverine, as well as some Enterobacteriaceae $(S$. liquefaciens). During the first two weeks of storage, C. divergens V41 was dominant in the inoculated product (count of LAB one to two $\log _{10}\left(\mathrm{CFU} \mathrm{g}{ }^{-1}\right.$ ) higher than in control), which 
may explain the inhibition. After three weeks, no difference in biogenic amine concentration was observed between control and inoculated CSS. At this time, LAB count in inoculated CSS is the same as in control and the ratio C. divergens V41 / spoilage micro-organism may be too small to observe an inhibition. It is also possible that strains (particularly Lactobacillus spp.) present in batches B and C differ from batch A and are unsensitive to divercin V41. Concentration of histamine in naturally contaminated batches B and C after 4 weeks of storage (respectively $397 \pm 45$ and $254 \pm 58 \mu \mathrm{g} \mathrm{g}^{-1}$ ) exceeded the European tolerated limit in Scombroids and Clupeids fish (mean of 9 samples $<100 \mu \mathrm{g} \mathrm{g}^{-1}$ and no sample higher than 200 $\mu \mathrm{g} \mathrm{g}^{-1}$, ECC 91/493). Free histidine, which is the substrate for histamine production, can be found in sufficient concentration in Salmo salar flesh to allow such production $\left(5860 \mu \mathrm{g} \mathrm{g}^{-1}\right.$ USDA nutrient database) and high levels of histamine have been found in routine control of smoked salmon in Denmark (Huss et al., 1995). The most effective methods for preventing biogenic amine formation are handling and processing under sanitary condition and temperature control $\left(<5^{\circ} \mathrm{C}\right)$ throughout the process. In our experiment, samples were stored at abuse temperatures $\left(8^{\circ} \mathrm{C}\right.$ for 19 days with a $2 \mathrm{~h}$ break at $\left.20^{\circ} \mathrm{C}\right)$. Concerning the sensory aspect, low differences between control and inoculated CSS was detected. Presence of $C$. divergens V41 in highly contaminated CSS slices was not detected by the trained panellists. On the other hand, this strain did not improved the quality of the product, but it clearly had been selected for its targeted antilisterial activity and not for controlling spoilage microorganisms. The inhibitory effect of $C$. divergens V41 against $L$. monocytogenes has been shown to be specifically related to the divercin V41 production (Richard et al., 2003). Although no bacteriocin was detected in the inoculated flesh in this set of experiment, the inhibitory effect of L. monocytogenes is effective (Brillet et al., 2004). Indeed, Duffes et al. (1999a) have emphasis those difficulties to measure divercin V41 in CSS, probably due to interaction with product and packaging, although inhibition was observed.

In conclusion, this study has shown that the strain C. divergens V41 inoculated in CSS in a biopreservation goal exhibits some interesting properties : it is able to grow at high level without giving major sensory changes in the product. This solution will not replace other measures for controlling L. monocytogenes (and spoiling microflora) in cold-smoked salmon but will act as an extra hurdle specifically designed to eliminate the listeriosis risk. To our knowledge, application of protective LAB is not common in fish products mainly because of their limited growth in chilled foods (Wessels and Huss, 1996) and production of off-odour (Nilsson et al., 1999). In CSS batches of high hygienic quality, some slight off-odours and flavours were detected in inoculated samples by a trained panel. Differences are so slight that it is believed that $C$. divergens V41 probably would not be detected by a non trained consumer panel. Some negative effects of $C$. divergens V41, such as slight productions of TVBN and tyramine, could be reduced by optimising C. divergens V41 level of inoculation while keeping an efficient inhibition of $L$. monocytogenes and by avoiding abused temperature storage. Lastly, work is currently under way to select tyramine negative mutants of C. divergens V41 for an application in CSS.

\section{Acknowledgements}

The authors would like to thank Mrs Josiane Cornet (IFREMER) for the data analysis with Fizz 2.00 software. This work was part of the "Aliment Qualité Sécurité" project $\left(\mathrm{n}^{\circ} \mathrm{R}\right.$ 01/05) and was supported by grants from the Ministry of Agriculture and Fishery, and from the European project "SEAFOODplus". 


\section{References}

Ben Embarek, P.K., 1994. Presence, detection and growth of Listeria monocytogenes in seafoods: a review. International Journal of Food Microbiology 23, 17-34.

Bledsoe, G.E., Flick, G.J., Gram, L., Herman, D., Jahncke, M.L., Ward, D.R., 2001. Processing parameters needed to control pathogen in cold-smoked fish. Journal of Food Science 66 (supp), 1055-1133.

Brillet, A., Pilet, M.F., Prevost, H., Bouttefroy, A., Leroi, F., 2004. Biodiversity of Listeria monocytogenes sensitivity to bacteriocin-producing Carnobacterium strains and application in sterile cold-smoked salmon. Journal of Applied Microbiology 97, 1029-1037.

Cardinal, M., Gunnlaugsdottir, H., Bjoernevik, M., Ouisse, A., Vallet, J.L., Leroi, F., 2004. Sensory characteristics of cold-smoked Atlantic salmon (Salmo salar) from European market and relationships with chemical, physical and microbiological measurements. Food Research International 37, 181-193.

Council Directive 91/493/EEC of 22 July 1991 laying down the health conditions for the production and the placing on the market of fishery products, Official Journal L 268 , 24/09/1991, pp. $0015-0034$.

Connil, N., Plissoneau, L., Onno, B., Pilet M.F., Prevost, H., Dousset, X., 2002. Growth of Carnobacterium divergens V41 and production of biogenic amines and Divercin V41 in sterile cold-smoked salmon extract at varying temperatures, $\mathrm{NaCl}$ levels, and glucose concentrations. Journal of Food Protection 62, 2, 333-338.

Connil, N., Prevost, H., Dousset, X., 2002. Production of biogenic amines and divercin V41 in cold smoked salmon inoculated with Carnobacterium divergens V41, and specific detection of this strain by multiplex-PCR. Journal of Applied Microbiology 92, 611-617.

Conway, E.J., Byrne, A., 1933. An absorption apparatus for the micro-determination of certain volatile substances. Biochemistry.27, 419-429.

Duffes, F., Corre, C., Leroi, F., Dousset, X., Boyaval, P., 1999a. Inhibition of Listeria monocytogenes by in situ produced and semipurified bacteriocins of Carnobacterium spp. on vacuum-packed, refrigerated cold-smoked salmon. Journal of Food Protection 62, 1394-1403.

Duffes, F., Leroi, F., Boyaval, P., Dousset, X., 1999b. Inhibition of Listeria monocytogenes by Carnobacterium spp. strains in a simulated cold-smoked fish system stored at $4^{\circ} \mathrm{C}$. International Journal of Food Microbiology 47, 33-42.

Edwards, R.A., Dainty, R.H., Hibbard, C.M., Ramantanis, S.V., 1987. Amines in fresh beef of normal $\mathrm{pH}$ and the role of bacteria in changes in concentration observed during storage in vacuum packs at chill temperatures. Journal of Applied Bacteriology 63, 427-434.

Eerola, S., Hinkkanen, R., Lindfors, E., Hirvi, T., 1993. Liquid chromatographic determination of biogenic amines in dry sausages. Journal of AOAC International 76, 575577. 
FAO yearbook, 2003. Fishery statistics : Commodities 2001, Vol. 93. Food and Agriculture Organization of the United Nation, Rome, pp.143.

Gram, L., Dalgaard, P., 2002. Fish spoilage bacteria--problems and solutions. Current Opinion in Biotechnology 13, 262-266.

Guyer, S., Jemmi, T., 1991. Behavior of Listeria monocytogenes during fabrication and storage of experimentally contaminated smoked salmon. Applied and Environmental Microbiology 57, 1523-1527.

Heinitz, M.L., Johnson, J.M., 1998. The incidence of Listeria spp., Salmonella spp., and Clostridium botulinum in smoked fish and shellfish. Journal of Food Protection 61, 318-323.

Joffraud, J.J., Leroi, F., Chevalier, F., 1998. Development of a sterile cold-smoked fish model. Journal of Applied Microbiology 85, 991-998.

Joffraud, J.J., Leroi, F., Roy, C., Berdague, J.L., 2001. Characterisation of volatile compounds produced by bacteria isolated from the spoilage flora of cold-smoked salmon. International Journal of Food Microbiology 66, 175-184.

Jorgensen, L.V., Dalgaard, P., Huss, H.H., 2000a. Multiple compound quality index for coldsmoked salmon (Salmo salar) developed by multivariate regression of biogenic amines and pH. Journal of Agricultural and Food Chemistry 48, 2448-2453.

Jorgensen, L.V., Huss, H.H., 1998. Prevalence and growth of Listeria monocytogenes in naturally contaminated seafood. International Journal of Food Microbiology 42, 127-131.

Jorgensen, L.V., Huss, H.H., Dalgaard, P., 2000b. The effect of biogenic amine production by single bacterial cultures and metabiosis on cold-smoked salmon. Journal of Applied Microbiology 89, 920-934.

Leisner, J.J., Millan, J.C., Huss, H.H., Larsen, L.M., 1994. Production of histamine and tyramine by lactic acid bacteria isolated from vacuum-packed sugar-salted fish. Journal of Applied Bacteriology 76, 417-423.

Leroi, F., Joffraud, J.J., Chevalier, F., 2000. Effect of salt and smoke on the microbiological quality of cold-smoked salmon during storage at $5^{\circ} \mathrm{C}$ as estimated by the factorial design method. Journal of Food Protection 63, 4, 502-508.

Leroi, F., Joffraud, J.J., Chevalier, F., Cardinal, M., 1998. Study of the microbial ecology of cold-smoked salmon during storage at 8 degrees $\mathrm{C}$. International Journal of Food Microbiology 39, 111-121.

Leroi, F., Joffraud, J.J., Chevalier, F., Cardinal, M., 2001. Research of quality indices for cold-smoked salmon using a stepwise multiple regression of microbiological counts and physico-chemical parameters. Journal of Applied Microbiology 90, 578-587. 
Lyhs, U., Bjorkroth, J., Hyytia, E., Korkeala, H., 1998. The spoilage flora of vacuumpackaged, sodium nitrite or potassium nitrate treated, cold-smoked rainbow trout stored at 4 degrees C or 8 degrees C. International Journal of Food Microbiology 45, 135-142.

Lyhs, U., Björkroth, J., Korkeala, H., 1999. Characterisation of lactic acid bacteria from spoiled vacuum-packaged, cold-smoked rainbow trout using ribotyping. International Journal of Food Microbiology 52, 77-84.

NF V 01-003, 2004. Hygiène et sécurité des produits alimentaires. Lignes directrices pour l'élaboration d'un protocole de test de vieillissement pour la validation de la durée de vie microbiologique. Denrées périssables, réfrigérées. Norme Afnor.

NF V 45-065, 1997. Poisson transformé. Saumon fumé. Norme Afnor.

Nilsson, L., Gram, L., Huss, H.H., 1999. Growth control of Listeria monocytogenes on coldsmoked salmon using a competitive lactic acid bacteria flora. Journal of Food Protection 62, 336-342.

Nykanen, A., Weckman, K., Lapvetelainen, A., 2000. Synergistic inhibition of Listeria monocytogenes on cold-smoked rainbow trout by nisin and sodium lactate. International Journal of Food Microbiology 61, 63-72.

Paludan-Muller, C., Dalgaard, P., Huss, H.H., Gram, L., 1998. Evaluation of the role of Carnobacterium piscicola in spoilage of vacuum- and modified-atmosphere-packed coldsmoked salmon stored at 5 degrees C. International Journal of Food Microbiology 39, 155 166.

Pilet, M.F., Dousset, X., Barré, R., Novel, G., Desmazeaud, M., Piard, J.C., 1995. Evidence for two bacteriocins produced by Carnobacterium piscicola and Carnobacterium divergens isolated from fish and active against Listeria monocytogenes. Journal of Food Protection 58, 256-262.

Ribeiro Neunlist, M., Ralazamahaleo, M., Cappelier, J.M., Besnard, V., Federighi, M., Leroi, F., In press. Effect of salting and cold-smoking process on the culturability, viability and virulence of listeria monocytogenes strain Scott A. Journal of Food Protection.

Richard, C., Brillet, A., Pilet, M.F., Prevost, H., Drider, D., 2003. Evidence on inhibition of Listeria monocytogenes by divercin V41 action. Letters in Applied Microbiology 36, 288292.

Rorvik, L.M., Caugant, D.A., Yndestad, M., 1995. Contamination pattern of Listeria monocytogenes and other Listeria spp. in a salmon slaughterhouse and smoked salmon processing plant. International Journal of Food Microbiology 25, 19-27.

Stohr, V., Joffraud, J.J., Cardinal, M., Leroi, F., 2001. Spoilage potential and sensory profile associated with bacteria isolated from cold-smoked salmon. Food Research International 34, 797-806.

Taylor, S.L., 1986. Histamine food poisoning : toxicology and clinical aspects. Critical Reviews in Toxicology 17, 91-128. 
Ten Brink, B., Damink, C., Joosten, H.M., Huis in 't Veld, J.H., 1990. Occurrence and formation of biologically active amines in foods. International Journal of Food Microbiology $11,73-84$.

Thurette, J., Membré, J. M., Han Ching, L., Catteau, M., 1998. Behavior of Listeria spp. in smoked fish products affected by liquid smoke, $\mathrm{NaCl}$ concentration and temperature. Journal of Food Protection 61, 1475-1479.

Truelstrup Hansen, L., Gill, T., Huss, H.H., 1995. Effects of salt and storage temperature on chemical, microbiological and sensory changes in cold-smoked salmon. Food Research International 28, 123-130.

Truelstrup Hansen, L., Huss, H.H., 1998. Comparison of the microflora isolated from spoiled cold-smoked salmon from three smokehouses. Food Research International 31, 703-711.

Truelstrup Hansen, L., Rontved, S.D., Henrik Huss, H., 1998. Microbiological quality and shelf life of cold-smoked salmon from three different processing plants. Food Microbiology $15,137-150$.

Vaz-Velho, M., Todorov, S., Ribeiro, J., Gibbs, P. In press. Growth control of Listeria innocua 2030c during processing and storage of cold-smoked trout by Carnobacterium divergens V41 culture and supernatant. Food Control.

Wessels, S., Huss, H.H., 1996. Suitability of Lactococcus lactis subsp. lactis ATCC 11454 as protective culture for lightly preserved fish products. Food Microbiology 13, 323-332. 
